\title{
Plantão Psicológico em Hospital e o Processo de Mudança Psicológica
}

\author{
Tatiana Hoffmann Palmieri Perches ${ }^{1}$ \\ Vera Engler Cury \\ Pontifícia Universidade Católica de Campinas
}

\begin{abstract}
RESUMO - Este artigo é fruto de uma Tese de Doutorado que objetivou evidenciar o processo de mudança psicológica significativa a partir de atendimentos de plantão psicológico sob a perspectiva da Abordagem Centrada na Pessoa (ACP), desenvolvida por Carl Rogers. Para tanto, a pesquisadora implantou um serviço de atenção psicológica aos funcionários de um hospital geral. Nesse tipo de atendimento, o fazer clínico apresenta-se como uma desconstrução do modelo tradicional, principalmente quanto às dimensões temporais e relacionais. A pesquisa buscou apreender fenomenologicamente os significados da experiência dos clientes por meio da construção de narrativas sobre os atendimentos realizados pela pesquisadora. Evidenciou-se um processo de mudança psicológica significativa no contexto do plantão psicológico que possibilitou aos clientes simbolizar as experiências vividas.
\end{abstract}

Palavras-chave: psicologia clínica, psicologia humanística, pesquisa fenomenológica, abordagem centrada na pessoa

\section{The Process of Psychological Change in a Walking in Clinic at a General Hospital}

\begin{abstract}
This article is the result of a PhD research which aimed to highlight the significant psychological process of change of clients who received psychological care based on the perspective of the Person-Centered Approach (ACP), founded by Carl Rogers. The researcher implemented a walking in clinic for employees of a general hospital as part of a psychological service. This kind of attendance led to a deconstruction of the traditional way of practicing clinical psychology, mainly on temporal and relational dimensions. The phenomenological method adopted in this study permitted to apprehend the meaning of the experience of the clients through narratives written by the researcher on the psychological attendance sessions. A significant psychological changing process was observed deriving from the walking in kind of attendance with positive impact to clients' symbolization of living experiences.
\end{abstract}

Key words: clinical psychology, humanistic psychology, phenomenological research, person centered approach

A partir da implantação de um Serviço de Plantão Psicológico, disponibilizado aos funcionários de um hospital geral, localizado em uma cidade do interior do Estado de São Paulo, emergiu uma questão relevante a ser pesquisada: o plantão psicológico desencadeia um processo de mudança psicológica no cliente? Este artigo tem como objetivo responder a tal questionamento, ao refletir sobre a presença de significativos elementos experienciais nessa modalidade de atenção psicológica clínica e, também, apresentar uma proposta de estratégia metodológica de inspiração fenomenológica que consiste na construção de narrativas. Os princípios norteadores estão embasados num diálogo entre a prática clínica contemporânea e a teoria que subjaz à Abordagem Centrada na Pessoa (ACP), desenvolvida por Carl Rogers na década de 50 do século passado nos Estados Unidos da América.

A modalidade de atenção psicológica denominada plantão psicológico tem se configurado como um modelo de ajuda psicológica desde 1979, ao ser implantada no Serviço de Aconselhamento Psicológico da Universidade de São Paulo (USP), despretensiosamente, com o objetivo de responder a demandas de natureza psicológica que não se adequavam

1 Endereço de correspondência: Rua Dom José Paulo da Câmara, 715 Jd. Paraíso, Campinas, SP, CEP 13100-027.

E-mail: perchest@yahoo.com.br às formas tradicionais assumidas pelas práticas clínicas em contextos institucionais de saúde pública, principalmente quanto às dimensões temporais e relacionais. É uma modalidade inovadora que acabou por democratizar o atendimento psicológico, isto é, apresentou-se como uma relação de ajuda oferecida a quem dela precisasse, imediata e inclusiva, ainda que sob uma perspectiva clínica rigorosa diante do sofrimento psicológico contemporâneo que se manifesta sob múltiplas faces. Assim, não é um modelo de atendimento psicológico pronto, mas uma prática psicológica flexível que abre possibilidades para a instituição na qual se insere e deve ser compreendida como um fenômeno que continuamente vai se reinventando a partir dos sentidos que lhe imprimem aqueles a quem serve (Furigo et al, 2006; Schmidt, 1999; Schmidt, 2009).

Do ponto de vista social, o plantão psicológico é uma modalidade de atenção clínica que vem se transformando ao se adequar a cada contexto no qual é implantado (Aun \& Morato, 2009; Barbanti \& Chalom, 1999; Oliveira \& Morato, 2009); sua prática e teoria tem se desenvolvido em decorrência das experiências vividas e relatadas pelos profissionais-plantonistas por meio de pesquisas levando a uma teorização sobre um tipo de atendimento que não se configura como preparação para um tratamento mais prolongado ou um substituto para o processo de triagem, comum nas Clínicas-Escolas (Eisenlohr, 1997; Schmidt, 1999). 
Constitui-se, assim, em um tipo de atenção psicológica diferenciado que pretende satisfazer as necessidades do homem contemporâneo, constantemente desafiado a mudar e adaptar-se, muitas vezes, à revelia de si mesmo. Além disso, o plantão psicológico mostra-se rico em potencialidade, exatamente por não assumir um contorno rígido e permitir inserções criativas quando aplicado a contextos e a pessoas diferentes (Bartz, 1997; Cautella, 1999; Cury, 1999a, 1999b; Mahfoud, 1987; Messias, 2002).

No Brasil, o Plantão Psicológico é uma prática com origem essencialmente institucional que vem se ampliando e solidificando no âmbito da Psicologia Clínica. Os psicólogos clínicos tem se defrontado continuamente com novas questões em contextos institucionais e tem procurado redefinir a concepção de Psicologia Clínica para responder às novas demandas (Tassinari, 2003). Insere-se aqui uma tomada de posição ampliada sobre atendimento clínico, libertando-o do viés tradicional, em que a psicoterapia era a única via possível para a atenção psicológica e longos processos terapêuticos eram sinônimos de tratamentos eficazes (Barbanti \& Chalom, 1999; Cury, 1999a; Mahfoud, 1987).

Como prática clínica, surgiu a partir da necessidade de se ter um espaço aberto às pessoas, muito mais do que aos problemas, promovendo, assim, a consciência de si e da realidade; levando o cliente a discriminar diferentes recursos disponíveis (Mahfoud, 1987). Esse tipo de atendimento também foi criado como forma de solucionar a grande demanda de clientes à espera de atendimento psicológico em instituições públicas e privadas, uma vez que muitas vezes essas pessoas podem beneficiar-se de um único encontro com um psicólogo.

O Plantão Psicológico, enfatizou Rosenberg (1987), não tem a intenção de substituir a psicoterapia e caracteriza cada atendimento como um universo único. Para Amatuzzi (1990), o objetivo do Plantão Psicológico consiste em propiciar a facilitação de um processo que é do cliente, portanto, a função do plantonista é acompanhar esse processo sem conduzi-lo. Cury (1999a) complementa caracterizando o atendimento de Plantão Psicológico como sendo de caráter emergencial que privilegia a demanda emocional imediata e espontânea do cliente.

A prática clínica da pesquisadora no contexto dos atendimentos de plantão constituiu-se em fenômeno sob a forma de um encontro intersubjetivo com cada cliente num processo específico que permitiu abordar a experiência humana imediata. Assim, o acontecer clínico pode ser descrito e compreendido a partir de seu impacto sobre a experiência do próprio plantonista (Cury, 1987). Nesta pesquisa, define-se mudança psicológica significativa como um processo de atribuição de significados às experiências, ou de sentido à angústia, a partir de determinadas atitudes por parte do plantonista: o exercício de uma escuta empática, de aceitação positiva incondicional acerca do mundo vivido pelo cliente e da expressão genuína de uma postura que privilegia compreender e não avaliar. Esse conjunto de atitudes inspira-se na proposta de Rogers (1942/1987) para uma relação autenticamente terapêutica que possibilita ao cliente significar suas experiências num processo de simbolização que é polissêmico e contínuo, isto é, uma dada experiência não pode ser apreendida no seu sentido original puro, pois ao ser comunicada, já adquire novos significados desdobrando-se em sentidos. Buber (1923/2001) afirma que a tomada de consciência acontece sempre em uma relação: é no encontro com o outro que posso aproximar-me de mim mesmo.

Assim, o atendimento psicológico pode ser caracterizado com um encontro dialógico que permite ao cliente assumir novos posicionamentos diante de si mesmo e do mundo, legitimando seu modo de ser e de sentir. Portanto, o plantão psicológico torna-se um exemplo de atenção psicológica na qual se estabelece um campo dialógico que supera o uso de técnicas para apoiar-se no compromisso humano e relacional. Bleger (1963) propõe o abandono de teorizações e de técnicas mecanicistas para se referir ao fenômeno humano, ao enfatizar a integração entre o campo experiencial e o teórico.

\section{O hospital geral como contexto da pesquisa}

Este trabalho foi desenvolvido em um hospital geral, localizado em uma cidade do interior do Estado de São Paulo, inaugurado há 11 anos e que, atualmente, atende a um fluxo grande de pessoas de cidades vizinhas. A população atendida pelo Hospital é composta de clientes particulares e por pessoas que têm convênio médico; não há atendimento ao público pelo Sistema Único de Saúde (SUS). Os serviços oferecidos aos clientes se dividem em atendimentos ambulatoriais, exames, pronto-socorro, cirurgias e internação (enfermaria, apartamentos, pediatria, maternidade e UTI).

O Serviço de Atenção Psicológica (SAP) foi implantado no hospital em 2004 pela própria pesquisadora e por outra psicóloga aos funcionários e a seus familiares e dispunha das modalidades de atendimento de plantão psicológico e psicoterapia. $\mathrm{O}$ horário de funcionamento era às quintas-feiras $\mathrm{e}$ sextas-feiras, das 9 h30 às 17h30. A psicóloga-pesquisadora atuou por quatro anos nesse Serviço, de forma voluntária, com o propósito de desenvolver a sua pesquisa de Mestrado e, posteriormente, a de Doutorado.

\section{Narrativas - desvelando os muitos sentidos do diálogo}

A experiência dos clientes foi apreendida, neste estudo, sob a forma de narrativas construídas pela pesquisadora que se mostraram especialmente produtivas, ao incluírem as fases de descrição, compreensão e interpretação do fenômeno intersubjetivo em suas diversas dimensões. A narrativa constituiu-se em uma autêntica expressão do encontro entre a plantonista e os clientes: no início do atendimento, caracterizado por um contato impessoal do cliente com seu próprio sofrimento, percebido como exterior a si mesmo, até a gradual aproximação em relação à experiência de angústia. Já que o princípio norteador de uma pesquisa fenomenológica é uma relação de implicação entre pesquisador e participante, a subjetividade da pesquisadora foi um elemento importante no processo de desvelamento da vivência clínica em relação ao fenômeno de mudança psicológica significativa desencadeada no cliente, a partir da experiência de ser atendido nessa modalidade de inter- 
venção psicológica (Amatuzzi, 1995, 2008; Goto, 2008; Moreira, 2001).

O estudo definiu-se ao redor da construção de quatro narrativas, geradas a partir dos atendimentos realizados no Serviço de Psicologia de uma instituição hospitalar pela própria pesquisadora. Tais narrativas foram inspiradas na prática clínica dos atendimentos de plantão psicológico e construídas de forma a não expor os clientes. Revelaram importantes elementos psicoterápicos presentes nesta modalidade de atenção psicológica que se constitui em um enquadre diferenciado em relação à psicoterapia tradicional por legitimar a demanda emocional do cliente no momento em que esta surge a ele como significativa.

A despeito de ter possibilitado uma compreensão sobre os elementos que emergiram nos atendimentos de forma dialógica e processual, a narrativa não se esgota em si mesma, já que as pesquisas são temporais e, em outro momento, esses mesmos significados podem ser desdobrados, pois significados se constroem e são transmitidos em função do caráter dinâmico que inspira a experiência humana.

A fim de tornar concreta a estratégia metodológica utilizada neste estudo, será reproduzida a seguir a narrativa sobre o atendimento de Júlia, personagem que sintetiza diversos clientes e suas formas singulares de expressão durante os atendimentos de plantão psicológico no contexto de um hospital geral.

Após a aprovação do projeto pelo Comitê de Ética em Pesquisa com Seres Humanos, a pesquisadora entrou em contato com os possíveis participantes para consultá-los quanto ao interesse em participar da pesquisa, explicando-lhes acerca dos objetivos. Foi agendado, então, um encontro individual com aqueles que manifestaram interesse durante o qual foi lido e devidamente assinado o Termo de Consentimento Livre e Esclarecido (TCLE). Os nomes usados são fictícios para preservar o anonimato.

\section{A história de Julia}

Júlia é uma mulher bonita, alta, ruiva e muito expansiva. Eu já a tinha visto no hospital antes dela marcar essa sessão de plantão psicológico e a imagem que me passara era de uma mulher forte, decidida, comunicativa e que andava de maneira firme (...) A princípio, queixou-se por sentir-se desanimada; depois disse que não era exatamente desânimo e buscou outra palavra: "chateada", mas, ainda assim, acrescentou: "não sei qual é a palavra, mas também não é chateada." Finalmente, satisfez-se quando encontrou a palavra "frustrada", pois percebi pela sua expressão de alívio o quanto the foi importante nomear seu sentimento. Continuou: "pois imagina que eu quis tanto um filho, mas agora não nos damos bem, e ele está com problemas com drogas. Vim aqui para saber se devo interná-lo ou não (...) Tenho quase 50 anos, não sou uma mãe adolescen$t e$ ". Não entendi sua alusão a não ser uma mãe adolescente, mas não a questionei. Perguntei-lhe sobre o que houve durante esse período para não se darem bem. Contou que já vinha tendo problemas no relacionamento com o marido, mas depois do nascimento do filho, começou a não se relacionar bem com os dois. Desde que se casou, há 15 anos, frustrou-se muito ao perceber as diferenças entre ela e o marido.
Depois de muitos anos na tentativa de resolver, sem sucesso, essas diferenças, ela decidiu ficar com o marido, porque o amava e tentou aceitar a situação, mesmo sem compreender porque ele não tentava mudar em alguns aspectos importantes, como o hábito de beber muito. Ela disse que como ele não procurava ajuda, acreditava que não queria mudar nesse aspecto. Comecei a entendê-la melhor quando complementou que ter um filho era um sonho que alimentara desde antes de se casar e, então, depois que ele nasceu se contentou em realizar esse sonho e deixar o anterior em segundo plano, o de ter um casamento feliz. Compreendi, então, o sentido de ter mencionado que não era mais uma adolescente, ao ouvi-la dizer que o "tempo" sempre fora uma questão de conflito para ela, como se estivesse sempre correndo contra ele, pois se casou com mais de 30 anos e sentia que estava tarde; quando sentiu vontade de se separar, achou que já era tarde para recomeçar, para mudar de vida, de casa; com o emprego foi a mesma coisa e naquele momento sentia que estava ficando tarde para ser feliz como mãe.

Ao ouvir a impressão da plantonista de que a despeito de ter sempre lutado contra o tempo para realizar o que desejava, ao mesmo tempo, ele parecia paralisá-la, Júlia assentiu e acrescentou que a possibilidade de ser tarde, de não dar tempo, não a deixava seguir em frente e realizar o que queria e salientou que, naquele momento, tal sentimento estava mais forte nela; sentia que estava diferente, "antes acho que eu era mais determinada, pelo menos, os outros me achavam, mas agora já não sei se isso era verdade ou só uma aparência falsa", ela disse. Prosseguiu, com um tom alterado, ao contar que foi impelida a ter que ser ou parecer forte, "pois, depois que men pai morreu, minha família me perguntava o que devia fazer sempre, e até hoje é assim, mas eu não aguento mais isso, não sou assim tão forte como eles gostariam". Indagada quanto a como realmente se sentia, respondeu que se sentia uma pessoa indecisa e fraca, com medo de tomar decisões. Disse que, às vezes, pensava que seu filho não tinha mais jeito, nem seu casamento e acreditava que a culpa era sua, por não tomar atitudes na hora certa, porque quando pensava que devia fazer algo, logo desistia, pois acreditava que eles poderiam mudar por si e, então, tudo melhoraria. "Eu poderia ter feito algo antes, mas nunca faço, entende. Até quando vou continuar assim?".

Assenti com a cabeça e houve um silêncio - que não me pareceu incômodo - então disse-lhe que compreendia como estava difícil para ela aceitar que não tomara atitudes que pareciam necessárias e sobre seu medo de continuar sendo assim. Em seguida, sinalizei que parecia haver uma mudança, já que estava tomando uma posição em relação ao filho daquela vez, ao procurar ajuda psicológica. Júlia disse que sabia que teria muitos problemas para resolver com essa decisão de interná-lo, mas queria muito fazer alguma coisa certa nesse sentido, "a maternidade sempre foi um sonho pra mim e agora preciso tomar essa decisão e sentir que sou boa mãe, pelo menos nisso quero me realizar".

Questionava-se sobre ser ou não uma boa mãe, se conseguiria enfrentar o que essa decisão exigiria. Isso a fez duvidar sobre estar pronta para tomar uma decisão, no entanto, deu-se conta de que não havia como prever e com um suspiro conformado, disse: "Pois é, mas como vou saber o que virá com uma decisão?". A partir daí, entrou em questões mais 
amplas acerca dessa posição de ser mais "dura" estar trazendo à tona problemas não resolvidos com o marido, com a família e, principalmente, com a família do marido que a rejeitava. Por esse motivo, não queria que o marido contasse para os pais dele o que estava acontecendo, mesmo entendendo que ele tinha esse direito e ele já dissera que queria dividir esse problema com eles.

Ao ser compreendida pela plantonista quanto aos motivos que a levaram a preferir que os pais do marido não participassem dessa problemática do filho, deu-se conta do quanto essa situação fez aflorar questões mal-resolvidas entre ela e o marido, que antes puderam ser evitadas. Júlia afirmou com uma voz firme e decidida que não queria a participação dos pais do marido, porque fizeram tudo para afastá-los (ela e o marido) e nunca a trataram bem: "para que contar a quem não vai dar apoio? Mas meu marido não entende, diz que o nosso filho vai ter que conviver com os avós, com os tios, e eu entendo que sim, mas tenho medo de deixar meu filho sozinho com eles e dele ser tratado mal'. Indagada se pelo fato dos pais do marido não gostarem dela, acreditava que não iriam tratar bem seu filho, Júlia disse que sim; que temia que ele se sentisse rejeitado naquele momento já tão delicado. Contou que, numa conversa seu marido discordou dela em relação a esse medo, ao dizer-lhe que ela poderia surpreender-se com eles. Então, ela gritou com ele dizendo coisas que, segundo ela, não sentia de verdade. Júlia declarou que tal fato acontecia num ímpeto, no sentido de se defender, que perdia a paciência e expressava o que não devia, nem o que realmente pensava, mas ele não a entendia e ficava sempre magoado.

Questionada se tal fato sempre acontecia enfatizou que sim, que não conseguia controlar-se e que seu marido já deveria estar acostumado. Levada a refletir quanto a essa certeza de que o marido compreendia bem esse modo dela reagir, houve, novamente, um silêncio e retomou dizendo que acreditava que ele deveria saber, que "era óbvio que ele sabia", mas, ao se acalmar, percebeu que talvez ele não soubesse como era o jeito dela funcionar realmente. Júlia achava que ele deveria compreendê-la já que conviviam por tantos anos, no entanto, pela reação dele, sempre tão ofendido e acuado com os desabafos dela, deu-se conta de que talvez ele não a conhecesse tão bem... Para ela, as brigas que tinha com o marido eram por falta de diálogo - ele não queria conversar com ela e não lhe respondia quando ela falava com ele - e essas discussões sempre acabavam com a concordância dele só com a cabeça e pedindo para voltar a ver TV. Ao refletir no quanto ela poderia estar contribuindo para que essas conversas importantes para eles se desenrolassem dessa forma, respondeu, de forma direta, que era uma pessoa crítica consigo e com todos e, na hora de falar, sempre parecia ser impositiva, forte, mas era porque precisava desabafar antes, para depois, conseguir escutar o que a outra pessoa tinha a dizer e se colocar no lugar dela; e continuou: "mas ele sempre fica impregnado pela primeira parte da conversa, dizendo que se eu estou dizendo isso, o que mais ele vai falar, já está decidido". Ela então respondia, já sem paciência, que não decidira, que precisava que conversassem mais para que pudesse escutar o que ele tinha a dizer, "mas ele não diz mais absolutamente nada, se acua ou se defende de mim e das nossas conversas, ficando mudo".
A dinâmica do plantão, naquele momento, concentrou-se na sua atitude, no modo como ela funcionava e como os outros a percebiam. Júlia deu-se conta de que havia uma falha nessa comunicação da qual antes não estava consciente, já que acreditava que era óbvio que quem convivia com ela deveria entender o seu jeito. Já no final daquele plantão, retomou o assunto de que não queria que o filho fosse maltratado pela família, e levantou uma dúvida: como ela poderia evitar que ele frequentasse a casa dos tios e avós e ainda que não a questionassem quanto ao motivo para tal? Ao tentar obter o controle da situação, percebi, então, o quanto essas questões estavam difíceis para ela; quando compreendida acerca do seu intuito de proteger o filho, já que seria tão difícil vê-lo sofrer, Júlia retoma o seu questionamento do início do plantão: “mas como prever o que acontecerá após uma decisão tomada?".

Antes de finalizarmos aquele encontro, essas questões quanto à proteção ao filho, e sobre o que os familiares poderiam fazer, foram ampliadas sob a forma de outros questionamentos: poupá-lo da convivência familiar, realmente, ajudaria? Como ajudá-lo a enfrentar a realidade - que, no seu caso, era a de enfrentar as consequências pessoais e sociais que seu problema de dependência química acarretariam e ainda o de pertencer a uma família que tinha conflitos entre seus membros? O que fazer diante dessa dicotomia: protegê-lo no intuito de evitar um possível sofrimento ou apenas apoiá-lo se ele viesse a sofrer? Será que protegê-lo dessa forma o impediria de amadurecer? Não foram aprofundadas e tampouco respondidas essas perguntas que, apesar de serem relevantes, ainda estavam dissociadas em Júlia, pois vieram dela como se fossem soluções para o problema do filho. Além disso, já havíamos passado da hora para encerrar o atendimento que já durara mais de uma hora. Então, avisei-a de que nosso tempo havia acabado e que ela poderia voltar se sentisse necessidade; a sessão foi encerrada com um abraço afetuoso de minha parte, plenamente correspondido por ela.

Ao refletir acerca desse plantão, ficou claro que a dor de Júlia fora legítima. Foi possível aprofundar a demanda psicológica trazida por ela e efetivou-se uma compreensão voltada a contribuir para que ela pudesse explorar mais o problema sem sentir-se ameaçada. O plantão durou cerca de uma hora e dez minutos, e ela demonstrou ter conhecimento de que a proposta era de um único encontro. Como a maioria dos clientes, ela chegou com uma questão concreta, objetiva a ser resolvida, que, durante o plantão, foi se desdobrando em outros questionamentos a partir de uma relação dialógica, o que fez emergir sentimentos e significados novos gerando novas vivências emocionais.

Apesar de ser óbvio que a situação era muito mais complexa do que aquele encontro pode abranger, acredito que clareamos algumas questões que a estavam paralisando e lhe causando muita angústia e raiva em relação a si mesma e aos seus familiares, já que ela sofria muito por sentir-se incompreendida pelo filho, pelo marido e rejeitada pela família dele. Essa situação impedia que ela e o marido pudessem se ajudar na tomada de decisão a respeito do problema que o filho estava enfrentando. Diante do exposto, questionei-me, durante a sessão, se deveria mostrar-lhe como o modo dela expressar-se não contribuía para facilitar um bom diálogo, já que, além do que ela descreveu, eu também o havia percebido na relação comigo (seu modo abrupto e crítico), mas sabia 
que soaria como uma crítica - o que não a ajudaria - pois era claro que ela mesma se incomodava com esse aspecto, apesar de não conseguir ser diferente, ao menos, até aquele momento. Para meu alívio, no decorrer da sessão, ela própria pode apreender isso, à sua maneira, ao perceber que o que ela esperava do marido deveria partir dela para com ele, ao ajudá-lo a entender o seu jeito para promover um melhor diálogo entre eles. Ao ter consciência do modo como funcionava no relacionamento com as outras pessoas, deu-se conta de que há uma falha nessa forma de comunicação sobre a qual não se dera conta até então; assim, ela pode significar, de forma diferente, o que acontecia entre ela e o marido, em parte, por ter sido capaz de olhar a situação sob outra perspectiva, durante o atendimento, exatamente por não se sentir ameaçada pela plantonista.

O sentimento de raiva que Júlia tinha em relação ao marido face a essas conversas frustradas entre eles, a partir desse novo significado atribuído por ela durante o plantão, pode dar espaço a outro sentimento que, para Júlia, foi de alívio. Por outro lado, ficou com raiva de si mesma ao perceber que não contribuíra para ajudá-lo a conhecê-la melhor, pois esperava que ele a entendesse por conta própria. $\mathrm{O}$ excerto a seguir expõe esse fenômeno teoricamente:

O mecanismo de repressão atua cegamente, atingindo não só o conteúdo ou a percepção que nos atemoriza, mas também a parte de nós mesmos que quereríamos conservar e cultivar. $O$ individuo pode sentir-se incapaz de amar enquanto não admite plenamente sua raiva, porque a abertura necessária não se fragmenta e, tal como a defesa, atua sutilmente sobre o ser inteiro. A difusão e a falta de delimitação dos processos de repressão surgem muito claramente no momento de sua reversão. Ao permitirmos a expressão do desamor ou do desinteresse, abrimos também caminho onde aparecem o afeto e o empenho, fenomeno que nosso raciocínio muitas vezes não previria (Rogers \& Rosenberg, 1977, p.13).

Apesar de Júlia dar-se conta de que pode melhorar seus relacionamentos ao perceber que essa sua dinâmica de esperar compreensão dos outros ocorre de modo mais amplo, e não apenas com seu marido, ainda terá que encontrar outros recursos inerentes a ela para poder conduzir, de forma diferente, os relacionamentos no seu cotidiano.

Júlia também ampliou o olhar diante de outro problema considerado por ela: o desejo de que o filho não mantivesse contato com os pais do marido, apenas com os seus, uma vez que o marido gostaria muito de ter os seus pais como participantes desse momento da sua vida. Essa imposição de Júlia de não aceitar esse compartilhamento vinha do desejo de proteger o filho da suposta rejeição ou de maus-tratos, já que, segundo ela, a família do marido não gostava dela e acreditava que eles poderiam querer afetá-la por meio do filho. Nessa questão, o desdobramento principal foram questões levantadas que não foram respondidas, pois colocadas de forma objetiva, chegaríamos ao que é mais "certo" ou "adequado" de se fazer, o que não provocaria mudança significativa já que tais questões são de caráter intelectual. Ainda assim, acredito que podem levá-la a pensar acerca de sua contribuição para manter as coisas inalteradas, se forem, de uma maneira pessoal e processual - conduzidas com referência aos seus próprios valores e sentimentos -, e não, impostas por outrem, no caso eu, como plantonista.

Em relação à pergunta inicial de Júlia - se deveria internar o filho - percebe-se que não voltou durante todo o tempo em que estivemos conversando, talvez porque fosse apenas a ponta do iceberg de questões mais profundas que foram desveladas e que, essencialmente, são parte da busca por uma maior congruência entre sua forma de agir e sua necessidade de sentir-se uma boa mãe e de obter mais apoio e compreensão por parte do marido.

Acrescenta-se, ainda, que gerar e criar filhos seria um exemplo da manifestação da tendência atualizante, já que envolve não só a satisfação de necessidades básicas e a especialização de órgãos e funções, mas também atividades mais complexas e mais evoluídas, como: " a revalorização do ser por meio de aprendizagem de ordem intelectual, social e prática (...) e o enriquecimento do indivíduo por meio da reprodução" (Rogers \& Kinget, 1977, p.160).

Para Júlia, constituiu-se, naquele momento, potencialmente, uma oportunidade de auto-realização e de investimento na facilitação da manifestação da tendência atualizante do filho. Há de se considerar também que a maternidade contemporânea traz desafios adicionais a enfrentar como, por exemplo, a conciliação da maternidade com o trabalho para a mulher e a maior demanda de dedicação do homem aos cuidados com os filhos.

Aiello-Vaisberg e Machado (2003) problematizam tal questão, ao apontarem que a aparente perda da complementaridade entre o feminino e o masculino que a contemporaneidade trouxe tem acrescentado certo incômodo às relações interpessoais de homens e mulheres, o que talvez leve a um rearranjo desses elementos que, "se produz confusão e sofrimento, também inaugura a possibilidade de configurações sequer imaginadas" (p. 76), o que conduz a novos questionamentos éticos.

Quais significados ou que continuidade ela dará a essas questões que ampliou durante o atendimento do plantão, não há como saber. Cabe a Júlia atribuir novos significados aos desdobramentos feitos; o mais importante foi que saiu do plantão compreendendo mais sobre si mesma, aceitando-se melhor, e esses sentimentos e significados sobre si mesma já são um começo; assim, cabe a mim, apenas confiar no seu desejo de crescimento e de mudança.

Finalmente, penso que algo moveu-se no interior de Júlia, ao procurar por esse tipo de atendimento, pois precisou abrir mão da fachada de mulher forte para revelar-se frágil; ao fazê-lo pôde experienciar novos significados sobre si mesma e, quanto aos problemas que a trouxeram, ainda estavam lá ao final do plantão, à espera de uma tomada de decisão dela. No entanto, por ter sido capaz de desfazer o modo habitual de considerar seus relacionamentos, talvez possa estar mais apta a lidar com a difícil tarefa de ser mãe que apenas se iniciou ao ter começado a ser uma melhor cuidadora de si mesma.

\section{O plantão psicológico revisitado}

Evidenciou-se que o momento da busca espontânea do cliente pelo atendimento de plantão é motivado pela vulnerabilidade que a experiência da angústia promove nele; há 
a presença de um acontecimento de vida que o ameaça, por lhe faltar um sentido; o atendimento viabiliza-se a partir do que mobiliza no cliente, levando-o a readquirir autonomia, retomando seu processo de crescimento psicológico. $\mathrm{O}$ plantonista deve oferecer-se como um outro que é capaz de legitimar a angústia do cliente, por meio de atitudes terapêticas que facilitem a busca pelo significado da experiência, ao atualizá-la subjetivamente, para além das contingências que a vida impõe. O plantonista deve estar atento e disponível, porém sem a expectativa de um próximo encontro como premissa para a solução do problema. Ambos, plantonista e cliente, têm sua consciência alterada nesse sentido. Os elementos essenciais para que esse tipo de relação de ajuda possa ser eficaz incluem a mobilização do cliente e a presença ativa do plantonista para disponibilizar o suporte psicológico necessário.

Esta pesquisa trouxe à luz um significativo potencial para a mudança psicológica, revelado em relação ao processo de mobilização gerado na pessoa ao tornar-se cliente de um plantão psicológico, levando-a a vislumbrar novos significados na direção da retomada da autonomia pessoal. A curta duração do encontro, colocada como um determinante, mostrou-se potencializadora para o estabelecimento de um vínculo afetivo importante, ao mobilizar o cliente a voltar-se para si mesmo a partir de uma preocupação autêntica do profissional que se concentra em conhecê-lo, pela via da empatia, ao mesmo tempo em que o confirma como alguém digno de confiança, pela via da aceitação incondicional. Por conseguinte, a dimensão temporal torna-se uma aliada para o objetivo dessa modalidade de atenção psicológica, pois permite a atualização da historicidade por meio da peculiaridade desse encontro intersubjetivo. Sabemos que, psicológica e fenomenologicamente falando, uma hora pode ser vivida como uma eternidade, e a eternidade pode ser vivida como um instante.

Trata-se de uma relação intersubjetiva que afeta a ambos os participantes, tendo como finalidade facilitar o encontro do cliente consigo mesmo e, em consequência, com seu crescimento pessoal. Entende-se que, na modalidade de plantão psicológico, esse processo também ocorre como em qualquer outra modalidade de intervenção psicológica, no entanto, cada modalidade e cada contexto tem suas peculiaridades. Destacam-se, a seguir, alguns elementos que caracterizaram o processo de mudança psicológica apreendido nos clientes a partir do atendimento de plantão psicológico pela pesquisadora no contexto de um hospital geral.

Durante esses atendimentos, que foram realizados pela pesquisadora, individualmente, emergiram novos significados em relação ao questionamento inicial que trouxe os clientes ao plantão: a partir de um sentimento de desconforto emocional, aprofundou-se a demanda psicológica trazida ao encontro, e foi inevitável o sentimento de frustração por parte deles, ao perceberem que não poderiam, simplesmente, distanciar-se dos seus problemas, ao despejá-los no psicólogo; mas, ao contrário, tiveram que se apropriar dessas vivências de forma subjetiva, ao intuírem que suas queixas/ problemas eram intrínsecos a eles, e não, objetos externos como os representavam no início; para tanto, tiveram que mobilizar um "olhar para dentro de si mesmos". Nesse percurso, a ansiedade tomou conta dos clientes, tatearam seus sentimentos, como medo, frustração, confusão, insegurança, na iminência de entrar em contato com o real questionamento daquele momento. Ao conseguirem aproximar-se de elementos subjetivos importantes, vivenciaram a angústia de forma iminente; e esta, durante o plantão, vai sendo uma força propulsora para o desdobramento de outros questionamentos e para a significação da experiência a partir de uma relação dialógica.

Apesar das questões serem mais abrangentes e profundas do que aquilo que foi experienciado no encontro de plantão, este trouxe à luz pontos que paralisavam os clientes. Puderam enfrentar novas descobertas sobre si mesmos adquirindo consciência sobre o modo como se relacionam consigo mesmos e com outras pessoas; puderam reconhecer suas incongruências. Este processo não ocorreu sem sofrimento emocional, pois, ao mesmo tempo em que assumiram novos elementos à consciência sobre si mesmos, também os rejeitaram, buscando preservar a auto-estima. Ainda assim, sentiram, invariavelmente, uma dose de alívio, ao significarem à sua maneira o que antes lhes parecia não ter sentido, ao perceberem que muitas questões não eram de responsabilidade do outro, como entendiam antes, enquanto outras não eram de responsabilidade e nem estavam sob controle deles, como lhes seria mais satisfatório. Encararam, portanto, o difícil dilema de abandonar certas percepções em função de estarem em contato com uma nova realidade emocional que lhes surgiu como inegável, quando submetida à prova da experiência pessoal; renderam-se a si mesmos no encontro com o outro, abriram mão de posturas rígidas que os mantinham impermeáveis ao novo, para revelarem-se frágeis naquele momento e foram recompensados pela apreensão de novos significados sobre si mesmos e sobre suas preocupações e sofrimento emocional. Ao final do atendimento, já não se olhavam da mesma forma e foram capazes de desfazer o modo habitual de considerar seus problemas; puderam estar mais aptos a lidar com a difícil tarefa de apropriarem-se de si mesmos e a tomar uma posição pessoal diante daquele momento da vida.

Nesse sentido, dispor-se a facilitar a experiência imediata dos clientes, permitiu a plantonista significar sua função no desencadeamento de um processo intersubjetivo não ameaçador que potencializou ao cliente observar-se em funcionamento, sem precisar armar-se de defesas contra as próprias percepções. Ao ser compreendido em relação aos seus piores sentimentos de forma profunda - a partir dos seus significados - o cliente pode abrir-se a novos sentimentos; a ausência de julgamento na relação promove a aceitação do que considerava inaceitável, pois, dizer algo de maneira autêntica a si mesmo numa relação com alguém significativo diminui as contradições entre o campo fenomenal e o self. Os clientes permitiram-se, então, experienciar seu self de muitas e peculiares maneiras ao longo do atendimento de plantão. Tem-se, então, a angústia como reveladora do sentido mais profundo daquele seu momento de vida, e a fala nesse contexto, torna-se restauradora da experiência, pois facilita uma simbolização adequada das experiências vividas.

Os encontros de plantão psicológico constituíram-se, portanto, em uma oportunidade para abertura psicológica e, ao mesmo tempo, de desafio para que os clientes pudessem rever seus modos de ser no mundo. Nesse sentido, Amatuzzi 
(1990) esclarece que o que deve ser buscado num atendimento psicológico é "a intencionalidade do significado" (p. 25) e, não exatamente, o sentimento deve ser o parâmetro de busca do psicoterapeuta (Gendlin, 1984), porque a intencionalidade é composta de significados implícitos, enquanto a experienciação aparece e se expressa a partir de uma relação.

Buber (1982) afirma ser no espaço da intersubjetividade que podem emergir os sentidos e significados dos envolvidos na relação. Assim, o plantonista também esteve imerso na relação e experienciou uma busca por sentido em relação ao cliente e a si mesmo, sendo desafiado como alguém que se dispõe a acolher o sofrimento alheio na hipótese de ser capaz de contribuir para o processo de reintegração psicológica.

A busca nos encontros foi pelo domínio de um sentido que oferecesse coerência, ou seja, embora a plantonista soubesse que o contexto (hospitalar) em que estava inserida ajudava a compreender o cliente - pois os sentidos e significações também vêm da dinâmica das relações sociais -, buscou, principalmente, o sentido próprio, aquele que é mais essencial a cada pessoa. Amatuzzi (1989) evidencia que essa forma de interpretação é baseada numa ética que se fundamenta na crença do potencial do outro para a geração de novos sentidos; assim, não se pode escutar o outro literalmente, pois a expressão da fala é uma procura, uma tentativa de simbolização. Esse tipo de interpretação se dá num clima de reciprocidade; pois, somente ao vivenciar-se uma relação, podem surgir novos sentidos e estes não serão, exclusivamente, do psicoterapeuta ou do cliente, mas, segundo Buber (1982), será um sentido construído no entre, serão dos dois.

Apesar de o agente da mudança psicológica ser atribuído ao diálogo humano e genuíno entre dois seres humanos a partir do encontro, cabe aos clientes continuarem o trabalho de atribuir novos significados a esses desdobramentos feitos, e deve o plantonista apenas confiar no desejo de crescimento e de mudança dos clientes e na capacidade natural de simbolização do ser humano. Nesse contexto, mudança psicológica significativa refere-se à mudança na percepção da pessoa e à retomada da autonomia pessoal, já que a fala significativa do cliente abre possibilidades; o que evidencia, assim, não os fatos, e sim, o processo de consciência.

Fica evidente que o papel do psicoterapeuta é deixar a pessoa com o reconhecimento das questões que enfrenta (Rogers, 1942/1987), no entanto, ações práticas e mudanças no padrão de comportamento da pessoa podem vir a ocorrer.

Nesse sentido, a atitude de empatia apresentou-se como um movimento afetivo-cognitivo do plantonista em direção à perspectiva fenomenológica do cliente. A partir da intimidade do terapeuta com a experiência do cliente e da relação dialógica construíram-se os significados e sentidos do vivido, e apresentou-se a intersubjetividade em movimento. A atitude de aceitação incondicional da vivência psicológica por parte do plantonista surpreendeu o cliente, pois o primeiro não se propôs a mudar a representação que o cliente apresentava sobre si mesmo, porém, exigiu dele uma nova afirmação de si. Atitudes de aceitação positiva incondicional e de empatia comunicadas pelo plantonista, ao longo do atendimento, tornaram-se essenciais no desencadeamento de um processo de crescimento psicológico no qual o sentido das experiências contadas foi mobilizado e potencializou um produtivo reencontro consigo mesmo, portanto, uma disponibilidade emocional autêntica por parte do plantonista possibilitou que o cliente se apropriasse do espaço clínico.

Assim, a relação não se constituiu como uma relação de mão única em que apenas um fala para o outro, e o outro o ajuda (Buber, 1982). Evidenciou-se a importância da reciprocidade e da mutualidade na relação, trata-se do fenômeno de ambos serem interpelados e se transformarem mutuamente - a simbolização adequada ocorre a partir da fala e da escuta genuína de ambos ao longo do processo. Assim, essa modalidade de atenção psicológica sob a perspectiva humanista-fenomenológica passa pelo processo de quebra do discurso mecanizado em prol de um modelo relacional, que traz embutido em si uma dimensão do ouvir que provoca o contato com o outro. Foi por meio da relação e da expressão de suas vivências que o cliente pôde mobilizar em si mudanças psicológicas; portanto, torna-se crucial, na relação de ajuda psicológica, o ouvir e o responder de forma mútua e autêntica. A partir do encontro intersubjetivo, ocorreu a integração de alguns elementos psicológicos, pela apropriação da sua própria dinâmica psicológica, ou mesmo, apenas uma aproximação do que se passava dentro de si é o que permitiu um grau maior de integração e, assim, o potencial de cada cliente encontrou-se mais plenamente liberado para atuar e aproximar-se do que "realmente se é", ao menos, naquele momento.

Enfim, nos atendimentos de plantão psicológico, priorizou-se a compreensão do cliente em sua dimensão total como pessoa, ao considerá-lo na expressão mais profunda da sua experiência; a qual foi presentificada e singularizada a partir da relação dialógica que compõe-se de comunicação, consciência, sentimentos, intencionalidade e atitudes. Assim, não basta apenas uma consciência acerca dos fatos, mas sim, dos significados, e é necessária a implicação pessoal de ambos nessa exploração. Por isso, pode-se dizer que a modalidade de plantão psicológico baseia-se na crença de que o ser humano é digno de confiança, capaz de desenvolver e de exercer seu potencial como pessoa, mesmo que, às vezes, necessite da ajuda de outra pessoa, no caso, o psicólogo, para se reorganizar e atuar com todos os seus recursos internos já existentes, pois é a partir da relação com o outro, que o ser humano apropria-se de si mesmo, da sua subjetividade única e singular - contradição que se apresenta como condição inevitável do ser humano. Além de que não há como apreender as vivências e significados originais do outro, pois estes são tecidos e apreendidos por meio da relação, do diálogo e a partir do contexto pessoal e histórico.

\section{Referências}

Aiello-Vaisberg, T. M. J., \& Machado, M. C. L. (2003). Ser e Fazer na Maternidade Contemporânea. Estudos de Psicologia, 20(2), 71-76.

Amatuzzi, M. M. (1989). O resgate da fala autêntica. Campinas, SP: Papirus.

Amatuzzi, M. M. (1990). O que é o ouvir. Estudos de Psicologia, $7(2), 86-97$.

Amatuzzi, M. M. (1995). Descrevendo processos pessoais. Estudos de Psicologia, 12(1), 65-80. 
Amatuzzi, M. M. (2008). Por uma Psicologia Humana. São Paulo, SP: Ed. Alínea.

Aun, H. A., \& Morato, H. T. P. (2009). Atenção psicológica em instituição: plantão psicológico como cartografia clínica. In H. T. P. Morato, C. L. B. T. Barreto, \& A. P. Nunes (Eds.), Aconselhamento Psicológico numa perspectiva fenomenológica existencial: uma introdução (pp. 121-138). Rio de Janeiro, RJ: Guanabara Koogan.

Bartz, S. S. (1997). Plantão Psicológico: atendimento criativo à demanda de emergência. Interações, 2(3), 21-37.

Barbanti, L. F., \& Chalom, M. H.(1999). Um serviço de plantão psicológico em instituição judiciária: ilustração prático-teórica. In H. T. P. Morato (Ed.), Aconselhamento psicológico centrado na pessoa: novos desafios (pp. 187-205). São Paulo, SP: Casa do Psicólogo.

Bleger, J. (1963). A psicologia da conduta. Porto Alegre, RS: Artes Médicas.

Buber, M. (1982). Do diálogo e do dialógico. São Paulo, SP: Ed. Perspectiva.

Buber, M. (2001). EU e TU. São Paulo, SP: Centauro. (Originalmente publicado em 1923)

Cautella, W. J. (1999). Plantão Psicológico em hospital psiquiátrico: Novas Considerações e Desenvolvimento. In M. Mahfoud (Ed.), Plantão Psicológico: Novos Horizontes (pp. 97-114). São Paulo, SP: Editora Companhia Ilimitada.

Cury, V. E. (1987). Psicoterapia Centrada na Pessoa: Evolução das Formulações sobre a Relação Terapeuta - Cliente. Tese de Mestrado não-publicada, Universidade de São Paulo, São Paulo.

Cury V. E. (1999a). Plantão Psicológico em clínica-escola. In M. Mahfoud (Ed.), Plantão Psicológico: novos horizontes (pp. 120-135). São Paulo, SP: Editora Companhia Ilimitada.

Cury V. E. (1999b). Psicólogos de Plantão... In M. Mahfoud (Ed.), Plantão Psicológico: novos horizontes (pp. 135-138). São Paulo, SP: Editora Companhia Ilimitada.

Eisenlohr, M. G. V. (1997). Formação de alunos em psicologia: Uma possibilidade para educadores. Dissertação de Mestrado não-publicada, Universidade de São Paulo, São Paulo.

Furigo, R. C. P. L., Sampedro, K. M., Zanelato, L. S., Foloni, R. F., Ballalai, R. C., \& Ormrod, T. (2006). Plantão psicológico: buscando romper com parâmetros clássicos da prática psicoterápica. In C. Ramos, G. G. Silva, \& S. Souza (Eds.), Práticas psicológicas em instituições: uma reflexão sobre os Serviços-Escola (pp. 80-98). São Paulo: Ed. Vetor.

Gendlin, E. T. (1984). The Client's Client: the edge of awareness. In R. F. Levant, \& J. M. Shilien (Eds.), Client Centered Therapy and the Person Centered Approach: New Directions in Theory, Research and Practice (pp. 3-22). New York: Praeger Publishers.
Goto, T. (2008). Introdução à Psicologia Fenomenológica: a nova psicologia de Edmund Husserl. São Paulo, SP: Paulus.

Mahfoud, M. (1987). A vivência de um desafio: plantão psicológico. In R. L. Rosenberg (Ed.), Aconselhamento Psicológico Centrado na Pessoa (pp. 75-89). São Paulo, SP: EPU.

Messias, T. S. C. (2002). Plantão Psicológico como possibilidade de facilitação de tendência atualizante: um estudo clínico. Dissertação de Mestrado não-publicada, Pontifícia Universidade Católica de Campinas, Campinas.

Moreira, D. (2001). O método fenomenológico na pesquisa. São Paulo, SP: Ed. Pioneira Thomson.

Oliveira, R. G., \& Morato, H. T. P. (2009). Uma experiência de plantão psicológico à Polícia Militar do Estado de São Paulo: articulando compreensões. In H. T. P. Morato, C. L. B. T. Barreto, \& A. P. Nunes (Eds.), Aconselhamento Psicológico numa perspectiva fenomenológica existencial: uma introdução (pp. 139-145). Rio de Janeiro, RJ: Guanabara Koogan.

Rogers, C. R. (1987). Psicoterapia e Consulta Psicológica (M. J. C. Ferreira, Trad.). São Paulo: Martins Fontes. (Originalmente publicado em 1942)

Rogers, C. R., \& Kinget, G. M. (1977). Psicoterapia e Relações Humanas: teoria da terapia não-diretiva Vol I. ( M. L. Bizzotto, trad.). Belo Horizonte, MG: Interlivros..

Rogers, C. R., \& Rosenberg, R. L. (1977). A Pessoa como Centro. São Paulo, SP: EPU.

Rosenberg, R. L. (1987). Aconselhamento Psicológico Centrado na Pessoa. São Paulo, SP: EPU.

Schmidt, M. L. S. (1999). Aconselhamento psicológico e instituição: algumas considerações sobre o Serviço de Aconselhamento Psicológico do IPUSP. In H. T. P. Morato (Ed.), Aconselhamento Psicológico centrado na pessoa: novos desafios (pp. 91-106). São Paulo, SP: Casa do Psicólogo.

Schmidt, M. L. S. (2009). O nome, a taxonomia, e o campo do Aconselhamento Psicológico. H. T. P. Morato, C. L. B. T. Barreto, \& A. P. Nunes (Eds.), Aconselhamento Psicológico numa perspectiva fenomenológica existencial: uma introdução (pp. 1-21). Rio de Janeiro, RJ: Guanabara Koogan.

Tassinari, M. (2003). A Clínica da Urgência Psicológica: Contribuições da ACP e da teoria do Caos. Tese de Doutorado não-publicada, Universidade Federal do Rio de Janeiro, Rio de Janeiro. 